\title{
As estratégias do Grupo Votorantim em meio à desindustrialização do Brasil: internacionalização, revisão do portfólio e mudanças na gestão do grupo (1980-2019)
}

Business Strategies by the Votorantim Group amidst Brazilian Deindustrialization Process: Internationalization, Portfolio Review and Changes in the Group's Management (1980-2019)

\author{
Gustavo Pereira da Silva \\ Universidade Federal de São Carlos (UFSCar), Brasil \\ gustavopsilva@ufscar.br \\ http://orcid.org/0000-0002-3943-6130
}

Armando João Dalla Costa

Departamento de Economia, Universidade Federal do Paraná (UFPR), Brasil ajdcosta@uol.com.br http://orcid.org/0000-0002-1016-7491 


\section{RESUMO}

O Grupo Votorantim foi criado em 1891, na cidade paulista de Sorocaba (Brasil). Desde 1930, passou a concentrar suas atividades no setor de bens intermediários (cimento, zinco, alumínio, produtos químicos e siderúrgicos), expandindo-se junto ao processo de industrialização do Brasil e convertendo-se no maior grupo privado da indústria nacional. Todavia, a partir dos anos 1980 - com a crise da dívida externa —, o modelo de industrialização liderado pelo Estado se perdeu e iniciou-se a desindustrialização do país. Neste artigo, analisam-se as estratégias da Votorantim para se adaptar à instabilidade econômica do Brasil pós-1980, utilizando como fonte os relatórios anuais do Grupo e apreendendo as seguintes estratégias: internacionalização, revisão do portfólio e mudanças na gestão do grupo no período de 1980 a 2019.

Palavras-chave: Votorantim, grupo econômico, internacionalização, portfólio, gestão, história econômica.

Códigos JEL: L61, N66, N86.

\section{ABSTRACT}

Created in 1891 in the city of Sorocaba, São Paulo, Brazil, the Votorantim Group started in the 1930s to concentrate its activities in the intermediate goods sector (cement, zinc, aluminum, chemical, and steel products), expanding along the industrialization process of Brazil and becoming the largest private group in the national industry. However, from the 1980s — with the foreign debt crisis - the state-led industrialization model became lost, giving way to the beginning of the country's deindustrialization process. This paper analyzes the strategies deployed by the Votorantim Group in order to adapt to the Brazilian economic instability after the 1980s, using the Group's annual reports as a source and understanding the following strategies: internationalization, portfolio review, and changes in group management during the period 1980-2019.

Keywords: Votorantim, business group, internationalization, portfolio, management, economic history.

JEL Codes: L61, N66, N86. 


\section{INTRODUÇÃO}

Neste artigo, embora haja divergências acerca do conceito de "business groups"(BG), utilizaremos a definição de Khanna e Yafeh (2007): "grupos normalmente compostos de empresas juridicamente independentes, que operam em várias indústrias (muitas vezes não relacionadas), que são ligados entre si por persistentes laços formais (por exemplo, patrimônio) e informais (por exemplo, família)" (p. 331). A escolha se deve ao fato de essa definição ser amplamente utilizada por trabalhos recentes e por abarcar os três aspectos centrais dos BG: presença de famílias no controle dos grupos; diversificação produtiva não relacionada, ou seja, que não se restringe às atividades centrais (core business); existência de subsidiárias independentes - empresas coligadas - que compõem o grupo e são atores importantes para a diversificação das atividades (Colpan \& Hikino, 2016; Barbero, 2011; Colpan \& Hikino, 2010; Carney et al., 2011; Bull, 2013; Yaprak \& Karademir, 2010).

No caso dos países atualmente considerados como economias emergentes, os BG apareceram como estrutura empresarial no começo e decorrer do século $X X$, tendo relevante papel no processo de industrialização do Brasil, da Argentina, do Chile, da Coreia do Sul, da China, da Índia, do México e de outros (Colpan et al., 2010; Carney et al., 2011). Nessas nações de mercados institucionalmente em formação - como proposto por Khanna e Palepu (1997), Khanna e Yafhe (2007) e originalmente por Leff (1974) — , um elemento comum seria a presença de vácuos institucionais: reduzida oferta de capital aos novos investimentos, dificuldade no acesso às matérias-primas e/ou às fontes energéticas, problemas de escoamento da produção, baixa oferta de trabalho qualificado.

A organização desses grupos, segundo Colpan e Hikino (2010), deu-se pela escolha de uma estrutura de propriedade piramidal, em que no vértice se encontra uma empresa central (holding) - a qual pode ter o controle de uma família - a liderar as subsidiárias independentes que atuam em setores cuja produção tende a ser não relacionada, ou seja, há uma propensão dos grupos econômicos à diversificação produtiva. Essas famílias empresárias - como os Ermírio de Moraes que lideram o Grupo Votorantim (Brasil) - exercem o controle das empresas alocando seus membros nos cargos de direção, possuindo a maioria das ações ou mesmo induzindo as firmas do grupo a financiarem os investimentos e a formação das subsidiárias, direcionando os rumos da diversificação produtiva e tendo grande relevância para 
a longevidade desses BG (Fernández-Pérez \& Lluch, 2015; Fernández-Pérez \& Casanova, 2012).

As vantagens geradas por esse modelo de organização empresarial baseiam-se nas constantes trocas de informações, nos recursos produtivos e na capacidade laboral e capital entre a controladora e as subsidiárias (Guillén, 2000; Khanna \& Palepu, 1997). Essas características dos grupos econômicos Ihes permitem atuar em diversos setores, obter economias de escala e escopo por meio da melhor utilização de recursos internos, maior poder de mercado, diminuição de riscos, ganhos de aprendizado, além de maiores fontes de capitalização do grupo por meio dos lucros de suas subsidiárias - compensando prejuízos com outras empresas ou setores do grupo (Granovetter, 2005; Delios \& Ma, 2010; Khanna \& Yafhe, 2007).

Ademais, os recursos produtivos mobilizados pelos BG são tidos como importantes indutores ao processo de internacionalização dos grupos, sobretudo em contextos de mudanças institucionais ou de políticas econômicas nos países emergentes - por exemplo, a crise da dívida externa na América Latina nos anos 1980. Em tal conjuntura, quando a incerteza econômica se torna aguda, os BG que se converteram em fortes competidores a partir do controle do respectivo mercado interno puderam buscar maior presença em escala internacional, sobretudo em setores cuja competição é global, como no de cimento (Yaprak \& Karademir, 2010; Yang et al., 2009; Aguilera et al., 2017; Dalla Costa et al., 2015; Santos, 2008).

No caso do Brasil, as famílias aparecem como controladoras da maioria dos BG - que são estruturas piramidais - a atuar no mercado nacional. Grande parte desses grupos são diversificados, pois atuam em, ao menos, três setores de atividade, sendo essa diversificação uma resposta às falhas de mercado (Aldrighi \& Postali, 2010). O elevado peso dessas grandes estruturas empresariais lhes possibilita um importante poder de barganha, quando os BG se alinham às políticas de desenvolvimento das nações emergentes, cenário que se deu a partir de 1930, no caso brasileiro, quando o Governo Federal comandou o processo de industrialização (state-led industrialization), valendo-se da entrada de BG estrangeiros e da formação de nacionais, corroborando para uma relação positiva entre a performance dos BG e a eliminação dos vácuos institucionais (Carney et al., 2011; Schneider, 2010; Guillén, 2000; Ocampo \& Ros, 2011).

Entretanto, essa aliança articulada e financiada pelo Estado, que angariava o capital privado nacional e estrangeiro, viu-se impossibilitada 
de permanecer em vários países da América Latina a partir da década de 1980, quando a região se viu engolfada pelas restrições de divisas impostas pela crise da dívida externa. Aldrighi e Postali (2010) mencionam que o Estado brasileiro teve que abandonar o papel estratégico de condutor do desenvolvimento econômico, passando a se concentrar nos esforços para o pagamento da dívida externa e nas tentativas malsucedidas de debelar a inflação, objetivos de política econômica que explicam a queda do investimento público no período.

Trabalhos recentes (Morceiro, 2018; Morceiro \& Guilhoto, 2019) têm mostrado que a década de 1980 pode ser considerada um turning point no processo de industrialização do Brasil. Isso porque, nos anos 1970, a participação da manufatura no produto interno bruto (PIB) do Brasil teve média de $20 \%$ e, desde 1980, essa participação tem recuado sistematicamente. Em 2018, a manufatura representava 11,3 \% do PIB - em valores constantes (preços de 2018) - , configurando um precoce e evidente processo de desindustrialização no país que suscita uma pergunta: qual teria sido o comportamento dos grupos econômicos em um cenário de instabilidade e baixo crescimento da indústria pós-1980? Para contribuir ao debate sobre as estratégias de sobrevivência dos BG na América Latina, vamos nos debruçar sobre o caso do Grupo Votorantim, um BG brasileiro criado em 1891, na cidade paulista ${ }^{1}$ de Sorocaba, e que permanece atualmente como um grupo de capital privado, familiar e fechado, destacando-se por ser o maior produtor nacional de cimento no Brasil e um dos dez maiores do mundo (Global Cement, 2018).

Segundo o ranking da revista América Economía, que se baseia na receita bruta de vendas em 2019, a Votorantim era o 530 maior grupo empresarial latino-americano, ficando na $18^{\text {a }}$ posição entre os grupos brasileiros. Sua atuação se dava no setor de cimento, mineração, metalurgia, aços longos, celulose, suco de laranja, energia e finanças. O grupo terminou o ano de 2017 com receita líquida consolidada de 30,9 bilhões de reais e lucro líquido de 4,9 bilhões de reais. As empresas do grupo estavam presentes no Brasil e em outros 19 países $^{2}$, empregando mais de 35 mil pessoas diretamente e mais 10 mil contratadas de terceiros - em 504 unidades operacionais e administrativas (América Economía, 2019; Relatório Anual do Grupo Votorantim [RAGV], Grupo Votorantim, 2018).

O termo "paulista" refere-se a algo relativo ao estado de São Paulo, Brasil.

2 Argentina, Brasil, Bolívia e Uruguai, na América do Sul; Canadá e Estados Unidos, na América do Norte; Espanha e Luxemburgo, na Europa; Turquia, na Europa/Ásia; Marrocos e Tunísia, na África. 
Os trabalhos de Silva e Dalla Costa (2018a, 2018b, 2021) abordaram a evolução do Grupo Votorantim, mas no período 1891-1979, ou seja, até o encerramento do ciclo de industrialização do Brasil. Por sua vez, a tese de Rocha (2013), as dissertações de Santos (2008) e Pedrosa (2015), bem como o artigo de Santos (2010) são relevantes contribuições que enquadram a trajetória da Votorantim em meio à formação de grupos empresariais no Brasil, tendo como foco o período a partir dos anos 1960 e mencionando sua internacionalização iniciada na década de 1980, mas que encerram suas análises por volta do ano de 2010, sem apreender os movimentos recentes do Grupo, tampouco articular essa análise com as evidências trazidas pela bibliografia sobre os BG no que tange à internacionalização. Ademais, esses trabalhos não abordaram o fenômeno da desindustrialização precoce do Brasil, cuja bibliografia tem se intensificado na atualidade.

O trabalho de maior fôlego desenvolvido por Santos (2012) trata-se de um esforço para sistematizar a trajetória das políticas de estímulo industrial e a formação de 26 grandes grupos econômicos industriais na Argentina, no Brasil, no Chile e no México. A densa análise do autor permite um bom panorama dos elementos indutores à internacionalização desses grupos tornando-se as multilatinas - e traz dados sobre o Grupo Votorantim até 2011, os quais buscaremos complementar com nossa análise que se estende até 2019.

Assim, o objetivo do artigo é abordar a trajetória do Grupo Votorantim a partir do ano de 1980 até 2019. Para tanto, é utilizada documentação primária (relatórios da diretoria do Grupo, demonstrações de lucros e perdas, balanços patrimoniais), destacando como se deu a reação às crises que afligiram a indústria nacional após o início da década de 1980, fato que levou o grupo a se internacionalizar em um primeiro momento, posteriormente a fazer ajustes em seu portfólio de investimentos e, no começo do século presente, a uma mudança administrativa. A percepção dessas estratégias é o fio condutor do trabalho, sempre considerando a confluência entre as mudanças na macroeconomia nacional e o impacto nas decisões do grupo. 


\section{A FORMAÇÃO DO GRUPO VOTORANTIM E SUA EXPANSÃÓ NO AUGE DA INDUSTRIALIZAÇÃO BRASILEIRA (1891-1979)}

A Fábrica Têxtil Votorantim foi criada na cidade paulista de Sorocaba, no ano de 1891, por iniciativa do banco União de São Paulo, o maior banco paulista naquele momento. Em 1918, a firma - uma das cinco maiores empresas têxteis do estado - compunha o rol de ativos do endividado banco (pequena central hidrelétrica, jazidas de cal e cimento, terrenos em São Paulo e no Paraná, Estrada de Ferro Votorantim) que, em processo falimentar, leiloou esses bens em janeiro do referido ano. Eles foram arrematados por Antonio Pereira Ignácio, Nicolau Scarpa e outros acionistas minoritários, formando doravante o Grupo Votorantim, que, já em 1919, tinha seu controle acionário nas mãos do português Pereira Ignácio, que era o diretor-presidente do grupo (Silva \& Dalla Costa, 2018a).

Em 1925, Pereira Ignácio trouxe seu genro aos negócios, o engenheiro pernambucano José Ermírio de Moraes, fazendo dele diretor-gerente em 1926, cargo que Ihe imputava a condução diária dos rumos da Votorantim e no qual ele permaneceu até 1962, quando foi eleito senador pelo estado brasileiro de Pernambuco. Nos 36 anos no comando executivo do grupo, ele empreendeu a grande guinada da Votorantim, que transitou do predomínio produtivo dos têxteis para o ingresso no setor industrial de base, notadamente nos ramos de cimento, siderúrgico, químico, metalurgia e alumínio (Caldeira, 2007) ${ }^{3}$.

Com a morte de José Ermírio em 1973, seus filhos (Antonio Ermírio de Moraes, José Ermírio de Moraes Filho, Ermírio Pereira de Moraes) e o genro Clóvis Scripilliti (casado com Maria Helena de Moraes) passaram a administrar a Votorantim, mantendo-a como um grupo familiar, de capital fechado e com foco na indústria de base ${ }^{4}$. Em 1978, a Votorantim era o segundo maior grupo empresarial privado brasileiro - atrás somente do banco

3 Na década de 1920, a produção de artigos têxteis de algodão representava 80 \% das receitas do Grupo Votorantim. Em 1979, os têxteis representavam apenas $3 \%$ das receitas da Votorantim (Silva \& Dalla Costa, 2021).

4 A Votorantim mantinha-se como um grupo econômico familiar e de capital fechado, presidido pelo patriarca José Ermírio de Moraes até 1973 - quando ele faleceu — e administrado da seguinte forma pelos quatro principais acionistas: ao primogênito José Ermírio de Moraes Filho (diretor-presidente), cabia gerenciar o setor de tecelagem, cimento no Sudeste e a indústria de filmes transparentes (Votocel); seu irmão Antônio Ermírio (diretor-gerente) cuidava do setor de metalurgia, sobretudo da Cia. Brasileira de Alumínio; ao cunhado Clóvis Scripilliti (diretor), ficavam os negócios na Região Nordeste (cimento Poty, usinas de açúcar e álcool); por fim, Ermírio Pereira da Moraes (diretor) estava incumbido da gerência da Cia. Nitro-Química (Caldeira, 2007). 
Bradesco - e, à época, compunha-se de 74 empresas (Aldrighi \& Postali, 2010; Caldeira, 2007; Grupo Votorantim, 1980).

Figura 1. Localização das empresas do Grupo Votorantim no território brasileiro (1980)

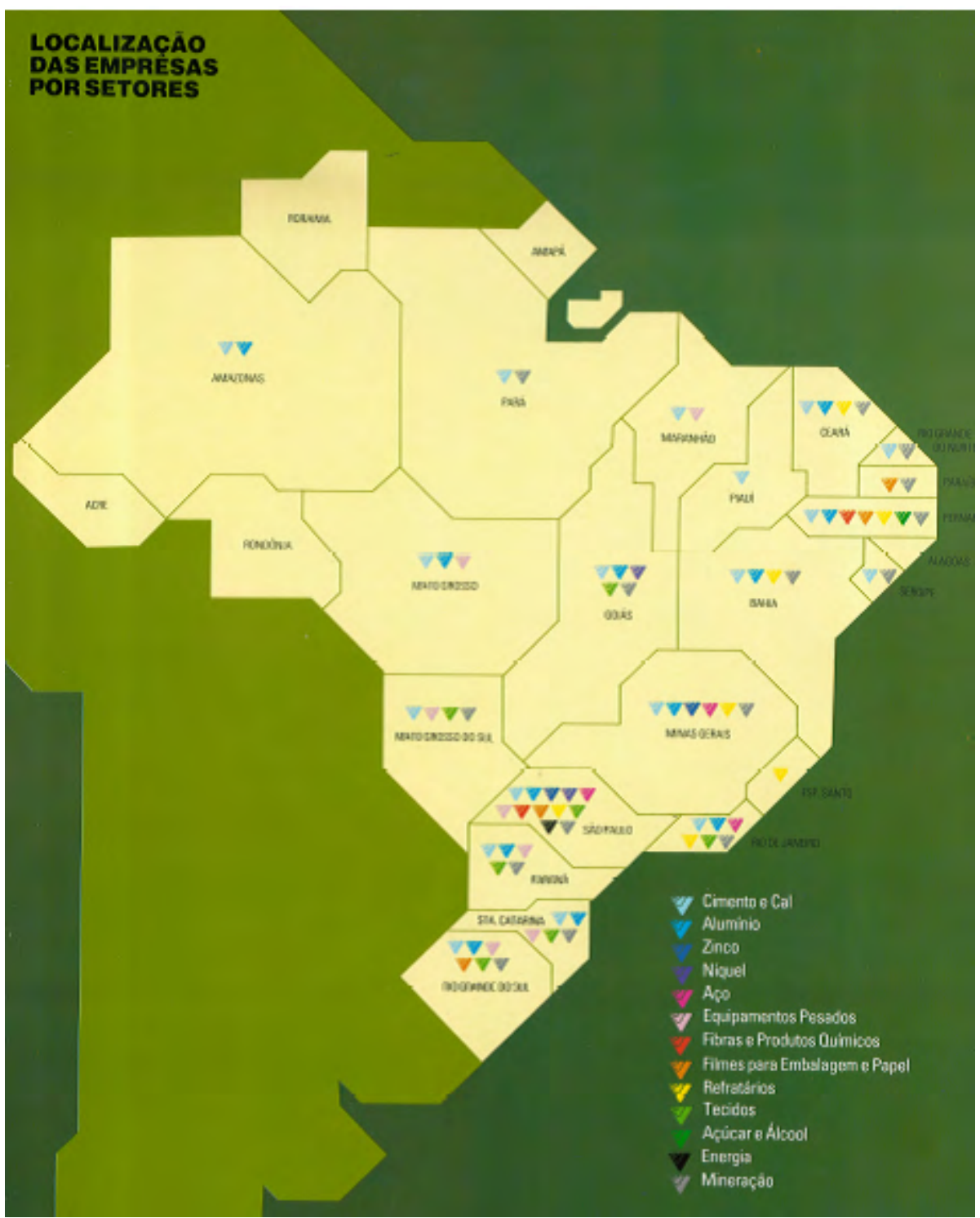

A figura 1 demonstra que as plantas industriais do Grupo Votorantim no início dos anos 1980 estavam espalhadas por todo o Brasil. Naquele momento, a produção de cimento - que só não se dava na Região Norte era responsável por $40 \%$ das receitas do Grupo, seguida pela produção de alumínio que representava $15 \%$ das receitas, de aço que era $7 \%$, fibras e produtos químicos, que eram $6 \%$, do zinco que também somava $6 \%$ das receitas. Dessa forma, a Votorantim expandia-se articulada ao modelo de 
desenvolvimento industrial brasileiro - período em que se desenrolava o II Plano Nacional de Desenvolvimento (1974-1979) —, cujo foco era completar a internalização dos setores de bens intermediários e de capital, a partir do ingresso do capital estrangeiro (multinacionais e dívida externa) e do robustecimento de grupos nacionais, como a Votorantim (Grupo Votorantim, 1979; Evans, 1980).

\section{O GRUPO VOTORANTIM E A CRISE NA INDUSTRIALIZAÇÃO BRASILEIRA NOS ANOS 1980}

A crise da dívida externa e a hiperinflação evidenciaram a fragilidade fiscal brasileira e, consequentemente, a derrocada da estratégia de desenvolvimento guiada pelo Estado (state-led industrialization) (Aldrighi \& Postali, 2010). Como reação, alguns grupos econômicos buscaram o mercado externo nos anos 1980, principiando uma fase de internacionalização de grandes empresas brasileiras (Dalla Costa et al., 2015). A venda de produtos ao mercado externo, a instalação de escritórios comerciais e depósitos em outras nações, subsidiárias de vendas e assistência técnica, além da eventual construção de plantas industriais em países estrangeiros faziam parte de uma estratégia de internacionalização de grandes empresas que haviam adquirido expertise no mercado interno e, agora, podiam ocupar faixas de mercado em nações vizinhas (Santos, 2008).

Em seu relatório de atividades concernente a 1983, quando o PIB brasileiro recuou -2,93 \%, o Grupo Votorantim exaltava o fato de não haver diminuído o número de seus funcionários (54 mil trabalhadores diretos), apesar de uma crise no principal ramo de atuação da empresa, pois o consumo nacional de cimento teve queda de $18 \%$ em relação ao ano anterior (Grupo Votorantim, 1983). 
Gráfico 1. Taxa de crescimento anual de alguns indicadores financeiros do Grupo Votorantim, 1980-1984 - valores em percentual

Fonte: RAGV (Grupo Votorantim, 1984, p. 2).

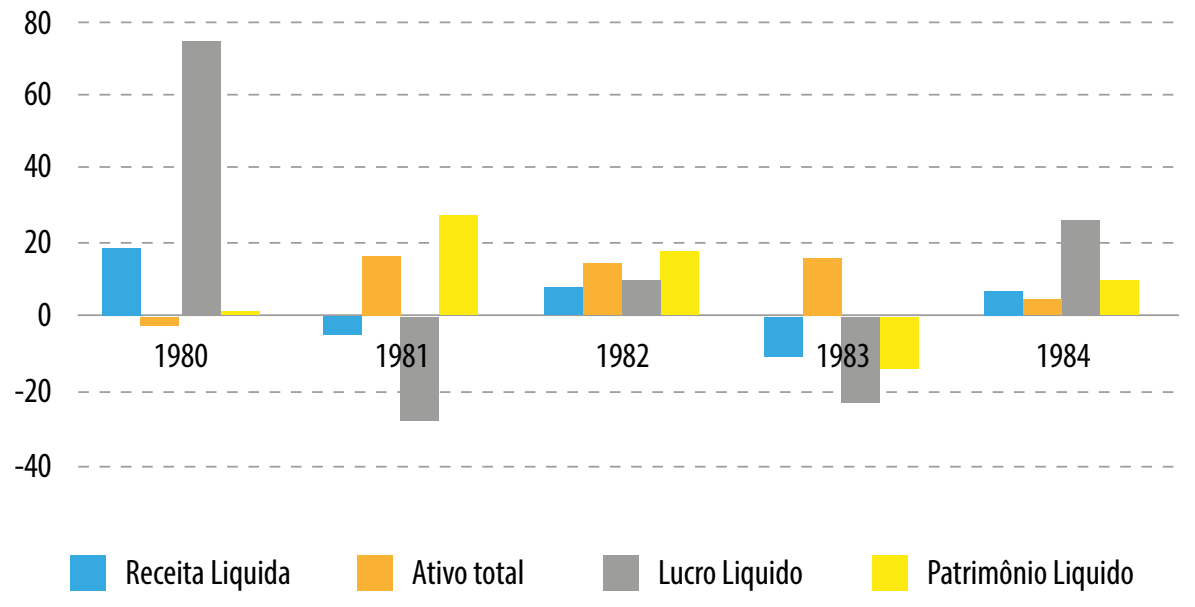

Por ser um grupo com a maior parte das receitas vinculadas ao mercado interno e, consequentemente, exposto às suas variações, o que se nota a partir de 1980 - com o gráfico 1 — é um comportamento errático dos indicadores financeiros, com relevante queda da receita e dos lucros em 1981 e em 1983, e uma leve recuperação em 1984, marcando a sintonia entre o desempenho da Votorantim e o mercado interno 5 .

Durante o decênio, como resposta à crise no cimento, reflexo do declínio do mercado interno, o Grupo estimulou as empresas subsidiárias a buscarem receitas no exterior, diretriz que transparece desde 1980, quando a Cia. Nitro-Química declarou que obteve um saldo favorável de 4,7 milhões de dólares com as exportações, sobretudo, de rayon e nitrocelulose (Grupo Votorantim, 1980). No mesmo relatório, anunciava-se que Cia. Brasileira de Alumínio implementaria um programa de aumento das exportações que, em 1984, permitiu à empresa alcançar a cifra de 61,7 milhões de dólares como receita das vendas ao exterior, para destinos como África, Ásia e até mesmo clientes europeus (Grupo Votorantim, 1981; Caldeira, 2007).

A busca por colocar seus produtos no mercado internacional seguiu com outras subsidiárias, como a Cia. Mineira de Metais e a Cia. Níquel Tocantins, que expandiram as exportações de zinco e níquel para países da América do Sul. Ademais, em 1984, a Votocel exportou $12 \%$ de sua produção de papel

5 Os resultados do PIB brasileiro no período foram os seguintes: no ano de 1980 (9,2 \%), 1981 (-4,3\%), 1982 (0,8 \%), 1983 (-2,9\%) e 1984 (5,4\%). No mesmo período, a taxa de investimento (Formação Bruta de Capital Fixo) caiu de 24\% do PIB para $19 \%$ (Giambiagi et al., 2005). 
transparente, iniciativa seguida pelas usinas do Grupo, que venderam ao exterior toda a produção açucareira naquele ano (Caldeira, 2007).

Na segunda metade dos anos 1980, a instabilidade do mercado interno ainda grassava, marcada pelo avanço da inflação - a taxa do Índice de Preços ao Consumidor Amplo (IPCA) em 1985 foi de 242 \% e chegaria a $1.972 \%$ em 1989. Para a Votorantim, setores vinculados ao mercado nacional - como têxtil, cimenteiro e metalúrgico - apresentavam uma relativa estagnação, conduzindo o grupo à aposta em novos investimentos que, com bom potencial no mercado internacional, pudessem ampliar as receitas de exportação (Bonelli, 1998).

Em 1987, a Votorantim adquiriu os ativos da Celpav, investindo 700 miIhões de dólares na unidade integrada para a produção de celulose branqueada de eucalipto e papéis de imprimir e escrever, localizada na cidade paulista de Luiz Antônio e que começou a produzir em 1992. Em 1989, o Grupo inaugurou a Citrovita, empresa voltada ao plantio de laranjais na cidade paulista de Itapetininga (Bonelli, 1998).

Cabe destacar que, em 1988, a Votorantim, estimulada pela possibilidade de lucros financeiros, abriu a Baltar D.T.V.M., empresa corretora e distribuidora de valores e títulos mobiliários que se tornaria, em 1991, o Banco Votorantim - o quinto maior banco privado do Brasil em 2019 (Banco Votorantim, 2018).

O balanço sobre o desempenho do grupo nos anos 1980 destaca que a Votorantim era o maior grupo econômico de capital privado no Brasil em 1988. Tal posição, que já havia sido alcançada há 10 anos, foi mantida a partir da expansão da função exportadora do grupo, como resposta à mudança no ambiente econômico-institucional do mercado interno em virtude da crise da dívida, elemento destacado na bibliografia dos BG por diversos autores (Yaprak e Karademir, 2010; Yang et al., 2009; Aguilera et al., 2017; Dalla Costa et al., 2015; Santos, 2008). Ademais, a Votorantim buscou ampliar pela diversificação em empresas voltadas a recursos naturais - papel e celulose, suco concentrado de laranja, nitrocelulose - tanto no sentido de se aproveitar de uma demanda interna e externa em expansão (suco concentrado de laranja) quanto de explorar ganhos de escopo em produtos que já eram relacionados ao que o Grupo executava (nitrocelulose, papel e celulose) (Santos, 2010; Khanna \& Yafhe, 2010; Khanna \& Palepu, 1997). 


\section{O GRUPO VOTORANTIM NA DÉCADA DE 1990: A BUSCA PELO FINANCIAMENTO EXTERNO E A CONCENTRAÇÃO DO PORTFÓLIO NO CORE BUSINESS}

Com o início da década de 1990, os efeitos das primeiras medidas econômicas do governo Fernando Collor reforçaram a crise do mercado interno. O confisco das aplicações financeiras efetuado pelo Plano Collor ( 16 de março de 1990), aliada à queda nas alíquotas de importação e à liberalização do câmbio - medidas que faziam parte da Política Industrial e de Comércio Exterior - criaram um cenário de aflição à indústria nacional que, por sua vez, não se traduziu na resolução dos problemas macroeconômicos nacionais: a inflação (IPCA) chegaria 2.477 \% no ano de 1993 e a soma do PIB no período Collor (de janeiro de 1990 a dezembro de 1992) teve resultado de $-3,8 \%$ (Castro, 2005).

No caso da Votorantim, houve a retenção de 600 milhões de dólares que constavam em seu caixa, equivalente a $80 \%$ de seus ativos financeiros. Para um Grupo que contava com 60 mil funcionários e uma folha salarial de 80 milhões de dólares, a solução de curto prazo foi paralisar momentaneamente os investimentos, tomar empréstimos, anunciar demissões que totalizaram 3 mil trabalhadores e ampliar ainda mais a presença no mercado externo, seja com a exportação de bens, seja com a tomada de crédito junto a bancos estrangeiros (Caldeira, 2007; Santos, 2008) ${ }^{6}$.

Nesse sentido, em 1992, o grupo criou a Votorantim Internacional, uma trading company que buscava intermediar os negócios entre as subsidiárias e os clientes estrangeiros, sobretudo, valer-se do mercado internacional como um sucedâneo à escassez de crédito de longo prazo na esfera nacional. Ao longo da década de 1990, a Votorantim Internacional se notabilizaria pela criação de escritórios comerciais em Hamburgo e Antuérpia, na Europa, em Newark e Baltimore, na América do Norte, em Cingapura, na Ásia, e em Newcastle, na Oceania. Essas representações visavam à prestação de serviços financeiros, fiscais, administrativos e logísticos, bem como a uma queda dos custos (seguros e fretes) de importação-exportação (Santos, 2010).

Um dos resultados dessa estratégia efetivou-se em 1996, quando a Votorantim obteve um empréstimo de 150 milhões de dólares junto ao

6 O quadro de crise foi descrito por Antônio Ermírio de Moraes (diretor-superintendente da Votorantim) ao indicar que "o governo 'quebrou a engrenagem da produção'. As empresas sobreviviam à base da exportação. No caso da Votorantim, nada menos do que $75 \%$ da produção de alumínio, bem como $55 \%$ do níquel e 30\% do aço eram exportados; enquanto isso, a Metalúrgica Atlas, a 'fábrica das fábricas', não tinha encomendas e limitava-se a serviços de manutenção" (Caldeira, 2007, p. 232). 
banco anglo-holandês ING Barings, destinado à divisão de papel e celulose da Votorantim. No ano seguinte, foi concedido mais um crédito de 50 milhões de dólares, dessa vez vinculado à expansão da Cia. Brasileira de Alumínio (Caldeira, 2007).
Tabela 1. Indicadores financeiros e patrimoniais do Grupo Votorantim, 19942006 - valores em bilhões de dólares

\begin{tabular}{|c|c|c|c|c|c|c|c|c|c|c|c|c|c|}
\hline & $\mathbf{1 9 9 4}$ & $\mathbf{1 9 9 5}$ & $\mathbf{1 9 9 6}$ & $\mathbf{1 9 9 7}$ & $\mathbf{1 9 9 8}$ & $\mathbf{1 9 9 9}$ & $\mathbf{2 0 0 0}$ & $\mathbf{2 0 0 1}$ & $\mathbf{2 0 0 2}$ & $\mathbf{2 0 0 3}$ & $\mathbf{2 0 0 4}$ & $\mathbf{2 0 0 5}$ & $\mathbf{2 0 0 6}$ \\
\hline Receita líquida & 2,6 & 3,3 & 3,0 & 3,2 & 3,1 & 2,8 & 3,4 & 3,5 & 4,0 & 5,1 & 6,4 & 9,7 & 13,3 \\
\hline $\begin{array}{c}\text { Porcentagem das expor- } \\
\text { tações na receita líquida }\end{array}$ & 27 & 22 & 19 & 19 & 19 & 25 & 26 & 26 & 28 & 23 & 20 & 16 & 16 \\
\hline Lucro líquido & 0,4 & 0,7 & 0,3 & 0,2 & 0,2 & 0,3 & 0,7 & 0,9 & 0,6 & 1,2 & 1,5 & 1,1 & 2,0 \\
\hline Investimentos & 0,3 & 0,5 & 0,7 & 0,8 & 1,0 & 0,4 & 0,5 & 1,7 & 1,0 & 1,2 & 1,1 & 2,5 & 2,5 \\
\hline EBTIDA & 0,7 & 0,9 & 0,6 & 0,6 & 0,7 & 0,9 & 1,3 & 1,2 & 1,4 & 1,9 & 2,2 & 2,5 & 3,7 \\
\hline
\end{tabular}

A tabela 1 indica que a década de 1990, em que pese a Votorantim ter Fonte: Caldeira (2007, pp. 238-239) se mantido como principal grupo privado a atuar no mercado brasileiro mensurado pelo tamanho do patrimônio líquido -, foi um decênio em que as receitas, o lucro líquido, os investimentos e o EBTIDA apresentaram baixo crescimento, em consonância com o resultado fraco da própria economia nacional, dado que o PIB do Brasil entre 1990 e 1999 alcançou uma taxa média anual de 1,75 \% - metade do crescimento médio anual do PIB mundial no período (Bonelli, 1998; Giambiagi, 2005).

A estratégia de permanências da Votorantim, em meio ao cenário instável da economia brasileira nos anos 1990, voltara-se à ampliação dos investimentos nos ramos anteriormente citados. Tal atitude fazia parte de uma reorientação encetada pelo Grupo Votorantim, que, com a crise na economia brasileira, adotaria um modelo de cresci mento com diversificação moderada, concentrando-se nos negócios que compunham seu core business (cimento, metais, agronegócio, papel e celulose, finanças e novos negócios) e, durante a década de 1990, desfazendo-se da atuação em áreas que não eram mais consideradas estratégicas (têxtil, filmes flexíveis, energia, biotecnologia), configurando-se como um grupo econômico orgânico (Santos, 2010; Schneider, 2010). 


\section{A REESTRUTURAÇÃO ADMINISTRATIVA DO GRUPO VOTORANTIM E SUA PLENA INTERNACIONALIZAÇÃO (2000-2008)}

A virada para os anos 2000 marcaria uma nova fase da Votorantim, com a reestruturação do comando administrativo do Grupo anunciada, em 30 de agosto de 2001, por Antônio Ermírio de Moraes. Naquela entrevista coletiva, foi informado que ele e os outros dois diretores da Votorantim desde os anos 1970 (José Ermírio de Moraes Filho e Ermírio Pereira de Moraes) deixariam o controle do cotidiano dos negócios para compor o recém-criado Conselho de Administração. Eles seriam responsáveis por orientar os membros dos dois conselhos que vinham logo abaixo na nova estrutura gerencial: o Conselho de Família e o Conselho Executivo, este último composto pelos primos (família Ermírio de Moraes) e responsável pela administração direta das empresas do grupo em suas respectivas áreas (Caldeira, 2007; Pedrosa, 2015) ${ }^{7}$.

Tabela 2. Unidades de negócio do Grupo Votorantim em 2001

\begin{tabular}{|c|c|c|c|}
\hline Área & Presidente & Vice-presidente & Negócios \\
\hline $\begin{array}{l}\text { Votorantim } \\
\text { Industrial }\end{array}$ & $\begin{array}{l}\text { José Roberto Ermírio de Moraes } \\
\text { (engenheiro metalúrgico pela } \\
\text { Fundação Armando Alvares } \\
\text { Penteado [Faap]) }\end{array}$ & $\begin{array}{l}\text { Fábio Ermírio de } \\
\text { Moraes (engenhei- } \\
\text { ro mecânico pela } \\
\text { Faap) }\end{array}$ & $\begin{array}{l}\text { Passou a agrupar os negócios tradicionais do } \\
\text { grupo: cimentos, metais, papel e celulose, } \\
\text { filmes flexíveis (Votocel) e a Votorantim } \\
\text { Internacional. }\end{array}$ \\
\hline $\begin{array}{l}\text { Votorantim } \\
\text { Negócios }\end{array}$ & $\begin{array}{l}\text { José Ermírio de Moraes Neto } \\
\text { (administrador de empresas } \\
\text { pela Fundação Getúlio Vargas } \\
\text { [FGV]) }\end{array}$ & $\begin{array}{l}\text { Cláudio Ermírio de } \\
\text { Moraes (engen- } \\
\text { heiro químico pela } \\
\text { Faap) }\end{array}$ & $\begin{array}{l}\text { Relacionada aos negócios que ainda não tinham } \\
\text { desempenho maduro, como as unidades dos } \\
\text { setores químico e a agroindústria. }\end{array}$ \\
\hline $\begin{array}{l}\text { Votorantim } \\
\text { Finanças }\end{array}$ & $\begin{array}{c}\text { José Ermírio de Moraes Neto } \\
\text { (administrador de empresas } \\
\text { pela FGV) }\end{array}$ & - & $\begin{array}{l}\text { Relacionada ao Banco Votorantim que era } 0 \\
\text { segundo maior banco de atacado no Brasil. }\end{array}$ \\
\hline $\begin{array}{l}\text { Votorantim } \\
\text { Energia }\end{array}$ & $\begin{array}{l}\text { Carlos Ermírio de Moraes } \\
\text { (engenheiro metalúrgico pela } \\
\text { Colorado School of Mines) }\end{array}$ & - & $\begin{array}{l}\text { Consolidação de todas as unidades de geração } \\
\text { de energia do grupo. }\end{array}$ \\
\hline $\begin{array}{l}\text { Votorantim } \\
\text { Novos } \\
\text { Negócios }\end{array}$ & $\begin{array}{l}\text { Luís Ermirio de Moraes (engen- } \\
\text { heiro químico pela Colorado } \\
\text { School of Mines) }\end{array}$ & - & $\begin{array}{c}\text { Seu objetivo era encontrar negócios promisso- } \\
\text { res a médio e longo prazo, principalmente nos } \\
\text { segmentos de biotecnologia e tecnologia da } \\
\text { informação. }\end{array}$ \\
\hline
\end{tabular}

O Conselho de Família existe desde 2001 e tem como estratégias desenvolver, apoiar e formar líderes e acionistas sustentáveis para a sucessão na família e nos negócios da Votorantim, bem como preservar o legado e os valores da família Ermírio de Moraes, cuidando da comunicação entre os membros e gerenciando o fluxo de informações sobre o negócio, as decisões e as relações familiares. A instância representa toda a família, que hoje já está na sua quinta geração. A composição desse conselho conta com sete membros, das terceira e quarta gerações, com idade acima de 26 anos (Grupo Votorantim, 2016). 
A tabela 2 demonstra que a Votorantim possuía, a partir de 2001, cinco unidades de negócio controladas pelos membros da família Ermírio de Moraes. A grande alteração em relação ao modelo prévio era que agora os negócios teriam uma administração mais próxima e centralizada, interligando unidades de negócio. Para Fernández-Pérez e Casanova (2012), essa reestruturação administrativa, aliada ao abandono de negócios menos rentáveis nos anos 1990, à manutenção de familiares com boa formação no comando dos postos estratégicos e à internacionalização, foram os fatores que permitiram ao Grupo Votorantim manter-se no tempo entre os maiores grupos econômicos do Brasil.

Nesse sentido, segundo Pastore (2013), "Antônio [Ermírio de Moraes] dizia que o caminho da internacionalização era um mal necessário para o Grupo poder crescer" (p. 154). Essa afirmação, feita em 2004, sintetiza um movimento de internacionalização de grandes empresas brasileiras a partir dos anos 2000, marcado por aquisições, fusões e joint ventures de empresas nacionais no mercado externo: exemplos foram a Petrobras, Gerdau, Cia. Vale do Rio Doce, Marcopolo e Friboi (Aguilera et al., 2017; Santos, 2008).

Mesmo que a contragosto, como nos leva a crer a fala de Antônio Ermírio, a internacionalização era vista pela nova geração de administradores da Votorantim como uma oportunidade de atuar em mercados que compensassem a trajetória de crescimento inconstante da economia brasileira desde a década de 1990, considerando que a maior parte das receitas do grupo vinha das vendas ao mercado interno. Outro indutor da internacionalização era o fato de alguns ramos, como o cimenteiro, serem altamente oligopolizados, com a presença de grandes firmas - Holcim (Suíça) e Lafarge (França) - que haviam iniciado suas respectivas internacionalizações desde os anos 1980 e, no início dos anos 2000, estavam adentrando ao mercado latino-americano (Yaprak \& Karademir, 2010; Yang et al., 2009). Ademais, a subida no preço das commodities - caso do zinco e do minério de ferro - , em que a Votorantim já atuava na exploração, pode ser considerada como um fator que levou a empresa a querer adquirir plantas nesses ramos produtivos em países estrangeiros (Santos, 2010) ${ }^{8}$.

8 O zinco teve uma valorização de quase quatro vezes naqueles anos, pois o preço da tonelada subiu de USD\$1.381,76, em 2000, para USD\$4.403,63, no final de 2006, cotações que majoraram sobretudo devido à alta na demanda por parte da China e dos Estados Unidos (Santos, 2010). 
Tabela 3. Aquisições do Grupo Votorantim no exterior, 2001-2008 (valores em milhões de dólares)

\begin{tabular}{|c|c|c|c|c|c|}
\hline $\begin{array}{l}\text { Empresa } \\
\text { adquirida }\end{array}$ & País-sede & Setores & Fábricas & Valor da aquisição & Ano \\
\hline Saint Mary's & Canadá & Cimento e concreto & Canadá & 720 & 2001 \\
\hline Suwanee & Estados Unidos & Cimento & Estados Unidos & $\begin{array}{c}50 \% \text { (100 milhões de } \\
\text { dólares) }\end{array}$ & 2003 \\
\hline $\begin{array}{l}\text { Badger Cement } \\
\text { Products }\end{array}$ & Estados Unidos & Moagem de cimento & Estados Unidos & - & 2003 \\
\hline $\begin{array}{l}\text { S\&W Materials } \\
\text { Inc. }\end{array}$ & Estados Unidos & Concreto & Estados Unidos & - & 2004 \\
\hline Cemex & México & Cimento & Estados Unidos & 400 & 2005 \\
\hline Prestige & estados Unidos & Concreto & Estados Unidos & 200 & 2007 \\
\hline Prairie & Estados Unidos & Concreto e agregados & Estados Unidos & Entre 400 e 500 & 2008 \\
\hline Bio & Chile & $\begin{array}{l}\text { Cimento, concreto } \\
\text { e agregados, cal e } \\
\text { cerâmica }\end{array}$ & $\begin{array}{c}\text { Chile, Peru, Venezuela, } \\
\text { Equador e Estados } \\
\text { Unidos }\end{array}$ & $\begin{array}{c}15,2 \% \text { (100 milhões de } \\
\text { dólares) }\end{array}$ & 2008 \\
\hline $\begin{array}{c}\text { Refinaria } \\
\text { Cajamarquilla }\end{array}$ & Peru & Zinco & Peru & 210 & 2004 \\
\hline $\begin{array}{l}\text { Companhia } \\
\text { Minera Milpo }\end{array}$ & Peru & Zinco & Peru, Chile & $\begin{array}{c}25 \% \text { (100 milhões de } \\
\text { dólares) }\end{array}$ & 2005 \\
\hline US Zinc & Estados Unidos & Zinco & Estados Unidos e China & 295 & 2007 \\
\hline Paz del Río & Colômbia & Aço & Colômbia & $\begin{array}{l}52 \% \text { do capital (491 } \\
\text { milhões de dólares) }\end{array}$ & 2007 \\
\hline $\begin{array}{c}\text { 9,9\% do } \\
\text { capital da Paz } \\
\text { del Río da em- } \\
\text { presa brasileira } \\
\text { Gerdau }\end{array}$ & Brasil & Aço & Colômbia & $\begin{array}{c}9,9 \% \text { do capital (63,3 } \\
\text { milhões de dólares) }\end{array}$ & 2008 \\
\hline Acerbrag & Argentina & Aço & Argentina & $\begin{array}{l}27 \% \text { do capital (60 } \\
\text { milhões de dólares) }\end{array}$ & 2008 \\
\hline Acerbrag & Argentina & Aço & Argentina & $\begin{array}{l}\text { Elevação da partici- } \\
\text { pação para } 52,9 \%\end{array}$ & 2008 \\
\hline
\end{tabular}

As aquisições de unidades produtivas no exterior, conforme a tabela 3 , serviram para posicionar a Votorantim entre os grandes players globais em alguns ramos: o grupo brasileiro tornou-se o terceiro maior produtor mundial de zinco em 2008 e o sétimo maior produtor global de cimento. As aquisições dessas plantas industriais, que totalizavam 13,6 bilhões de reais no ano de 2008, fizeram da Votorantim a quarta maior empresa brasileira com relação ao volume de ativos no exterior, a décima maior quanto ao número de países em que se encontravam as subsidiárias - 10 ao todo e a $19^{a}$ empresa brasileira mais internacionalizada (Fundação Dom Cabral [FDC], 2009). 
Ao êxito na internacionalização, combinava-se a manutenção na liderança de importantes ramos da produção nacional: como o cimenteiro, em que a Votorantim detinha 35 \% da produção nacional em 2013; com relação ao níquel, o grupo controlava $60 \%$ do mercado interno na década de 2000; a Cia. Brasileira de Alumínio era maior produtora nacional do metal em 2009 (Santos, 2008; Pedrosa, 2015). Somadas as receitas externas à liderança em importantes ramos da economia nacional, a Votorantim mantinha-se como um dos 10 dez maiores grupos econômicos do Brasil no início dos anos 2000, como aponta a tabela 4.

\begin{tabular}{|c|c|c|c|c|}
\hline Ranking & Grupo econômico & Ano de fundação & Origem do capital & Receitas de vendas \\
\hline 1 & Petrobras & 1953 & Estatal nacional & 218,2 \\
\hline 2 & Bradesco & 1943 & Privado nacional & 74,5 \\
\hline 3 & Vale & 1942 (privatizada em 1997) & Estatal nacional & 66,3 \\
\hline 4 & Itaú & 1945 & Privado nacional & 56,4 \\
\hline 5 & Banco do Brasil & 1808 & Estatal nacional & 55,4 \\
\hline 6 & Telefónica & 1998 & Espanhol & 41,1 \\
\hline 7 & Ambev & 1999 & Belga & 37,0 \\
\hline 8 & Votorantim & 1891 & Privado nacional & 35,3 \\
\hline 9 & Gerdau & 1901 & Privado nacional & 34,2 \\
\hline 10 & Fiat & 1899 & Italiano & 33,3 \\
\hline
\end{tabular}

\section{A CRISE ECONÔMICA MUNDIAL DE 2008 E O GRUPO VOTORANTIM (2008-2019): ANÁLISE DO DESEMPENHO RECENTE}

Para a economia brasileira, o estouro da crise financeira mundial (subprime) em setembro de 2008 - iniciada pela quebra do banco Lehman Brothers (Estados Unidos) - , notabilizou-se por não ter provocado uma queda prolongada do PIB - que foi de 0,13\% em 2009 e, no ano seguinte, atingiu o crescimento de 7,5 \% (Cardoso, 2013). Porém, quanto ao Grupo Votorantim, os efeitos de curto prazo foram significativos e, concomitantemente, ilustram a ciranda financeira que marcou a eclosão da crise.

Em 11 de outubro de 2008, a Votorantim fez um comunicado à imprensa para anunciar que o grupo havia auferido perdas em operações
Tabela 4. Os 10 maiores grupos econômicos do Brasil, 2007 (receitas de vendas em bilhões de reais)

Fonte: adaptada de Aldrighi e Postali (2010). 
financeiras com câmbio que atingiam 2,2 bilhões de reais ${ }^{9}$. Naquele ano, o braço financeiro era responsável por $30 \%$ das receitas do grupo, sobretudo pela atuação do Banco Votorantim - importante em segmentos como o crédito à aquisição de veículos - que, no mesmo ano, teve 49,99\% de suas ações compradas pelo Banco do Brasil (Barbieri, 2008; Pedrosa, 2015).

Pelo lado da economia real, a crise afetou a demanda externa de vários produtos que compunham o portfólio da Votorantim, o que implicou queda nos preços durante o ano de 2009: aço (-13\%), celulose (-15\%), suco de laranja (-40\%), níquel (-36\%), alumínio (-35\%) e zinco (-12\%). Com relação ao cimento, no mercado estadunidense, onde se situavam plantas industriais do grupo brasileiro, houve retração de 10 \% nas vendas; já no mercado interno, o consumo ficou estagnado em 51,5 mil toneladas entre 2008 e 2009 (Pedrosa, 2015; Sindicato Nacional da Indústria do Cimento, 2019).

Esse cenário adverso traduziu-se em queda de $-18 \%$ na receita bruta da Votorantim em 2009 e de -3,5 \% no patrimônio líquido, além de uma lucratividade (rentabilidade do ativo) nula no ano de 2008, consequência dos prejuízos assumidos pelo braço financeiro do grupo. Ademais, o endividamento como porcentagem do patrimônio líquido foi acrescido em 29 \% de 2007 para 2008 (Rocha, 2013).

Em meio à crise, a Votorantim passou por um processo de reorganização de suas atividades, cujo foco foi desfazer-se de alguns empreendimentos: em 2008, o grupo, que já havia perdido o controle acionário sobre o Banco Votorantim para o Banco do Brasil, vendeu ainda as empresas de biotecnologia em cana de açúcar Canavialis e Alellyx para a Monsanto por cerca de 290 milhões de dólares; em 2011, a Cia. Nitro-Química foi vendida ao fundo de investimento Faro Capital (Rocha, 2013).

Todavia, houve um acréscimo importante ao grupo que foi a aquisição da Aracruz Celulose para a formação da Fibria, operação efetuada em 2009 e que gerou a maior produtora mundial de celulose de eucalipto. Outro ponto a destacar foi a fusão da Citrovita (Grupo Votorantim) com a Citrosuco em 2010, criando a maior produtora mundial de suco concentrado de laranja superando a também brasileira Cutrale (Pedrosa, 2015). agosto, depois de quatro anos de alta, os exportadores que apostavam a favor do real tiveram os prejuízos" (Barbieri, 2008, p. 1). 
O cimento voltou a ser a principal atividade do Grupo Votorantim desde 2009 e, em 2018, a atividade gerou 38 \% das receitas, seguida pela Nexa ${ }^{10}$ com $27 \%$, Cia. Brasileira de Alumínio com $16 \%$, Votorantim Energia com $13 \%$ e Aços Longos 6 \% (Grupo Votorantim, 2019). Sincronicamente ao comportamento do PIB brasileiro, o consumo nacional de cimento teve trajetória ascendente entre 2009 e 2014, mas, desde então, vem apresentando queda, refletindo o próprio declínio do PIB que acumulou uma retração de $-4,7 \%$ entre 2015 e 2018, afetando os resultados financeiros do Grupo Votorantim.

\begin{tabular}{|c|c|c|c|c|c|}
\hline \multicolumn{1}{|c|}{} & $\mathbf{2 0 1 5}$ & $\mathbf{2 0 1 6}$ & $\mathbf{2 0 1 7}$ & $\mathbf{2 0 1 8}$ & $\mathbf{2 0 1 9}$ \\
\hline Receita líquida & 29,3 & 26,7 & 27,2 & 31,9 & 30,9 \\
\hline $\begin{array}{c}\text { Lucro líquido } \\
\text { EBTIDA (segmento } \\
\text { industrial) }\end{array}$ & 0,382 & -1 & 0,81 & 2 & $4,9^{*}$ \\
\hline Dívida líquida & 7,0 & 4,3 & 4,8 & 6,9 & 5,1 \\
\hline Dívida líquida/ EBTIDA & $2,79 \mathrm{x}$ & $3,43 \mathrm{x}$ & $2,60 \mathrm{x}$ & $1,91 \mathrm{x}$ & $1,95 \mathrm{x}$ \\
\hline
\end{tabular}

A tabela 5 evidencia que o biênio 2015-2016 foi árduo ao Grupo Votorantim, apresentando queda na receita líquida, prejuízo ao invés de lucro, diminuição do EBTIDA e um expressivo e preocupante aumento em sua alavancagem demonstrada pela evolução do indicador dívida líquida/ EBTIDA esses indicadores melhoraram após 2017, espelhando o crescimento - mesmo que incipiente — da economia brasileira, cujo PIB ficou em torno de 1 \% no triênio 2017-2019.

Após a crise econômica mundial de 2008, que gerou perdas financeiras e alavancagem ao Grupo, cessado o ciclo de preços favoráveis das commodities e mantido a trajetória de crescimento baixo da economia brasileira e retração do setor manufatureiro na formação do PIB, a Votorantim mantém-se no rol dos importantes grupos econômicos nacionais, mas não mais na condição protagonista em que se habituou até 2007: segundo o ranking Valor 1000, a Votorantim teve a 19a maior receita líquida em 2017.

A perda de posição relativa teve como uma de suas determinantes a concentração das atividades do grupo no mercado interno, posto que
Tabela 5. Resultados financeiros do Grupo Votorantim, 2015-2019 (em bilhões de reais)

Fonte: RAGV (Grupo Votorantim, 2015-2019).

*Obs.: essa expressiva elevação do lucro líquido do ano de 2019 em relação ao ano anterior se deve à finalização da venda da Fibria (fabricante de celulose) para o Grupo Suzano, operação que foi finalizada em 2019.
10 Em 2017, houve a união da Votorantim Metais, empresa líder de mineração de zinco no Brasil, e a Milpo, líder no Peru, originando a Nexa Resources, concentrada na mineração de zinco em escala mundial. Por sua vez, a Votorantim Energia trata-se da empresa formada em 2000 para administrar as usinas energéticas do grupo e que, recentemente, adentrou ao ramo de usinas eólicas e transformou-se na maior autoprodutora privada de energia no Brasil (Grupo Votorantim, 2018). 
apenas $30 \%$ do EBTIDA vinha das plantas industriais da Votorantim no exterior. A desindustrialização e as fragilidades da economia brasileira desde 2014 - quando o PIB cresceu somente 0,50 \% - têm sido apontadas pelos relatórios do grupo como entraves à expansão das receitas: as flutuações cambiais, sistema tributário complexo e oneroso, deficiências logísticas e aumento do salário real sem a mesma contrapartida em produtividade (Grupo Votorantim, 2014).

De modo a contrabalançar as crises no mercado interno, o Grupo Votorantim manteve sua importante estrutura produtiva no exterior ${ }^{11}$, com presença em mais de 20 países entre 2011 e 2018, tratando-se de um robusto processo de internacionalização que se deu sobretudo na primeira década dos anos 2000, quando adquiriu a maioria das plantas industriais em outros países (Santos, 2013). Em 2015, para exemplificar a importância das vendas externas, $46 \%$ das receitas do grupo vieram das unidades no exterior, segundo o ranking da Fundação Dom Cabral, o Grupo Votorantim era a $11^{\text {a }}$ empresa mais internacionalizada do Brasil em 2018 (FDC, 2018). No que se refere às plantas produtivas no exterior, pode-se destacar (Grupo Votorantim, 2011-2018):

- ano 2010 - a Votorantim Cimentos comprou participação na Cimpor empresa portuguesa de cimentos (adquiriu 17,3 \% das ações que antes eram da francesa Lafarge). A Votorantim Metais do Brasil consolidou sua participação com 50,02 \%, mediante uma oferta pública de ações, obtendo o controle da empresa peruana Milpo;

- ano 2012 - em um processo de troca de ativos com a Cimpor, empresa cimenteira portuguesa, a Votorantim Cimentos passou a atuar em seis novos países (Espanha, Índia, China, Turquia, Marrocos e Tunísia), além de contar com uma nova jazida no Peru. Também obteve o controle da empresa cimenteira Artigas no Uruguai, com o aumento da participação acionária;

- ano 2015 - a Votorantim ampliou a participação na mineradora peruana Milpo, o que representou um investimento de 368 milhões de reais que elevou a participação acionária da Votorantim na empresa para $60 \%$ em 2015. Em abril de 2016, a companhia voltaria a comprar ações ordinárias da mineradora peruana, ampliando sua participação para 80,24 \%;

11 No RAGV (Grupo Votorantim, 2016) para o ano de 2016, a "Mensagem da Administração" aponta que "o processo de internacionalização da companhia iniciado em 2001 e a diversificação dos negócios nos permitiram enfrentar as turbulências e reduzir os impactos derivados da queda no mercado brasileiro" (p. 5). 
- ano 2016 - a Votorantim Cimentos implementou medidas para reforçar sua liquidez financeira e perfil de endividamento de longo prazo, liderando a primeira emissão de bonds da sua Unidade St. Marys Cement, nos Estados Unidos, no valor de 500 milhões de dólares e vencimento em 2027. No segmento de polimetálicos, houve o aumento de $8 \%$ da receita líquida que foi impulsionado pelo acréscimo no volume de vendas, reflexo do aumento da produção de concentrados nas minas de Vazante (Brasil), Atacocha (Peru) e Cerro Lindo (Peru);

- ano 2017 - a Nexa Resources abriu o capital, com uma oferta pública inicial de ações nos Estados Unidos e no Canadá que alcançou boa receptividade de investidores. Na Votorantim Cimentos, houve a venda de ativos não estratégicos (como as unidades de cimento na China, no Chile e nos estados norte-americanos da Flórida e da Califórnia). Ainda na Votorantim Cimentos, foi inaugurada uma nova linha na fábrica em Sivas, na Turquia, o maior investimento da Votorantim Cimentos fora das Américas; a unidade de Yacuses, na Bolívia, concluída no fim de 2016, entrou em plena operação; nos próximos dois anos, o foco estaria nos projetos de expansão de Charlevoix, nos Estados Unidos, previsto para 2018, e de duas unidades na Argentina, para 2018 e 2019;

- ano 2018, Votorantim Cimentos - houve a conclusão do projeto de expansão da unidade de Charlevoix, nos Estados Unidos, adicionando 0,6 milhão de tonelada de capacidade. A criação de uma holding não operacional em Luxemburgo para consolidar investimentos internacionais. Houve a conclusão do desinvestimento em projetos no Peru e está em processo de conclusão o desinvestimento das operações da Índia, em uma estratégia de racionalização do portfólio de ativos e foco nos países com melhores perspectivas de geração de valor.

A internacionalização da Votorantim em meio ao cenário turbulento da economia nacional teve de ser mantida pelo grupo sem a presença do líder da terceira geração de comandantes, Antônio Ermírio de Moraes, que morreu em 24 de agosto de 2014. Naquele ano, a Votorantim iniciou uma reforma de seu modelo administrativo que buscou agregar pessoas de fora da família nos postos mais elevados da administração do grupo, bem como delimitar o espaço de participação dos familiares. Até a realização deste 
estudo, a estrutura administrativa do grupo encontra-se da seguinte maneira (Grupo Votorantim, 2019, pp. 29-33) ${ }^{12}$ :

1. Hejoassu (governança de propriedade) - holding proprietária da Votorantim, de capital fechado e familiar, cujo Conselho de Administração é formado por 12 acionistas, sendo três membros de cada uma das quatro holdings familiares proprietárias ${ }^{13}$;

2. Conselho de Família (governança de família) — em 2019, passou por nova eleição, sendo composto de sete membros, dos quais cinco são da quinta geração e dois, da quarta geração. Tem como missão formar acionistas responsáveis e desenvolver líderes para futuras sucessões familiares, bem como facilitar a comunicação dos negócios com a família;

3. Conselho de Administração (governança corporativa de negócios) - define o planejamento estratégico e orienta sobre as ações para executá-lo, além de deliberar sobre a alocação do capital; avalia periodicamente o desempenho dos conselhos de administração das empresas investidas/ subsidiárias, aos quais indica os conselheiros;

4. Diretoria Executiva (governança corporativa de negócios) — responsável pela condução dos negócios sob as diretrizes do Conselho de Administração;

5. empresas investidas/subsidiárias - cada uma conta com seu Conselho de Administração.

Tabela 6. Portfólio do Grupo Votorantim (2019)

\begin{tabular}{|c|c|c|c|c|c|}
\hline Empresa & $\begin{array}{c}\text { \% Votorantim } \\
\text { no capital }\end{array}$ & Ramo & Empregados & Unidades & Presença \\
\hline $\begin{array}{c}\text { Votorantim } \\
\text { Cimentos }\end{array}$ & 100 & $\begin{array}{c}\text { Materiais de cons- } \\
\text { trução (cimento) }\end{array}$ & 11.932 & 264 & $\begin{array}{c}\text { Argentina, Bolívia, Brasil e Uruguai; } \\
\text { Canadá e Estados Unidos; } \\
\text { Luxemburgo e Espanha; Turquia; } \\
\text { Marrocos e Tunísia }\end{array}$ \\
\hline Nexa & 64 & $\begin{array}{c}\text { Metais e mine- } \\
\text { ração (zinco) }\end{array}$ & 5.771 & 15 & $\begin{array}{c}\text { Brasil, Peru, Luxemburgo, Estados } \\
\text { Unidos e Coreia do Sul }\end{array}$ \\
\hline $\begin{array}{c}\text { Cia. } \\
\text { Brasileira } \\
\text { de Alumínio } \\
\text { (CBA) }\end{array}$ & 100 & Alumínio & 5.029 & 13 & Brasil \\
\hline
\end{tabular}

13 A família, que atualmente está na sexta geração, reúne 158 pessoas, entre elas 41 acionistas do Grupo Votorantim (Grupo Votorantim, 2019). 


\begin{tabular}{|c|c|c|c|c|c|}
\hline $\begin{array}{c}\text { Votorantim } \\
\text { Energia }\end{array}$ & 100 & Energia & 485 & 57 & Brasil \\
\hline Aços Longos & $\begin{array}{c}100 \% \text { na } \\
\text { Acerbrag e } \\
82 \% \text { na Acerías } \\
\text { Paz del Río }\end{array}$ & Aços Longos & 2.138 & 3 & Colômbia e Argentina \\
\hline Citrosuco & 50 & Suco de laranja & 5.331 & 46 & $\begin{array}{c}\text { Brasil, Estados Unidos, Austrália, } \\
\text { Bélgica, Japão, China e Áustria }\end{array}$ \\
\hline $\begin{array}{c}\text { Banco } \\
\text { Votorantim }\end{array}$ & 50 & Finanças & 3.972 & 87 & Brasil e Bahamas \\
\hline
\end{tabular}

A tabela 6 exibe o grande portfólio que compõe os negócios da Votorantim atualmente. Em 2018, o grupo havia optado por desfazer-se de alguns investimentos - vendeu a Fibria para a Suzano e a Votorantim Siderurgia para a Arcellor Mittal - e aprofundar sua inserção em setores considerados mais dinâmicos e estratégicos: adquiriu o controle acionário da Cia. Energética de São Paulo e consolidou sua posição como maior player nacional na geração privada de energia. A "Mensagem da Administração", presente no último relatório anual, ressalta o cenário de incerteza na economia mundial e de baixo crescimento no Brasil, conjuntura aguda até para um dos maiores e mais longevos dos grupos econômicos do país, que não encontra no mercado interno o dinamismo de outrora e, com relação às exportações e aos mercados estrangeiros, temia a escalada das disputas entre os Estados Unidos e a China.

\section{CONSIDERAÇÕES FINAIS}

Com 128 anos de existência, o Grupo Votorantim apostou desde seus primórdios no avanço do mercado interno, iniciando pela indústria têxtil, setor que foi a principal fonte de receitas do final do século XIX até 1930. A partir daquele decênio, houve uma transição ocorrida entre 1930 e 1980, em sintonia ao processo de industrialização nacional, com a produção de bens intermediários (cimento, siderúrgico, químico, metalurgia e alumínio), convertendo-se no core business do grupo as vendas de cimento, sendo a principal atividade, e a Votorantim se situou como o segundo maior grupo privado do Brasil ao final da década de 1970.

O espocar da crise da dívida externa e da escalada inflacionária no Brasil dos anos 1980 marcou a derrocada das políticas industrializantes e, como resposta por parte de grandes grupos econômicos nacionais, o início
Fonte: adaptada do RAGV (Grupo Votorantim, 2020, p. 10). 
de um processo de internacionalização. Tal processo continuaria no decênio seguinte, posto que o baixo crescimento do PIB brasileiro permaneceu, o que induziu a Votorantim a buscar a venda de seus produtos em nações estrangeiras e a tomar crédito junto a banqueiros internacionais.

Com o início do século XXI, o grupo passou por uma mudança administrativa que colocou em esferas diferentes a presença dos familiares (Conselho de Família) e a condução dos negócios (Conselho de Administração), incorporando pela primeira vez em postos diretivos pessoas que não pertenciam ao núcleo familiar. Essa reorganização administrativa se deu em meio à definitiva internacionalização produtiva da Votorantim, com a aquisição de plantas industriais na América Latina, nos Estados Unidos e na Europa, fazendo daquele que era o oitavo maior grupo econômico brasileiro também uma das empresas mais internacionalizadas do país.

Esse ciclo expansionista sofreu forte queda em 2008, com a crise econômica mundial. O braço financeiro da Votorantim acumulou importantes prejuízos e precisou ser em parte repassado ao Banco do Brasil. Ademais, outros negócios tiveram que ser vendidos — caso da Cia. Nitro-Química -, diante de um cenário que é o atual da economia brasileira: a desindustrialização e o baixo crescimento econômico.

De 2011 a 2018, além da reestruturação administrativa que se deu após 2014 - com a morte de Antônio Ermírio de Moraes - , a manutenção do processo de internacionalização da Votorantim foi um elemento a contrabalançar as flutuações econômicas no cenário brasileiro. De modo geral, constatamos que não houve grandes aquisições de plantas produtivas em outros países como na década inicial dos anos 2000, mas o que se deu foi a manutenção dessas unidades, com desinvestimentos pontuais - caso das unidades cimenteiras na China e no Chile - e alguns acréscimos relevantes, como os advindos da Europa a partir da troca de ativos com a portuguesa Cimpor e como a construção das unidades de cimento na Turquia, nos Estados Unidos (Charlevoix) e na Bolívia (Yacuses).

Considerando esses pontos, duas questões se colocam à manutenção do Grupo Votorantim no longo prazo: 1) dado que suas receitas vêm, na maioria, das vendas ao mercado interno, conseguirá o Grupo se expandir - ou mesmo sobreviver - em meio as mais demoradas das crises econômicas do Brasil republicano? 2) Sem poder mais contar com os capitães da terceira geração - o principal nome tendo sido Antônio Ermírio de Moraes —, como será a condução dos negócios que contam cada vez mais com 
indivíduos que não necessariamente têm os mesmos valores que trouxeram o grupo até aqui? Só o tempo poderá responder a tais indagações.

\section{REFERÊNCIAS}

Aguilera, R. V., Ciravegna, L., Cuervo-Cazurra, A. M. A., \& Gonzalez-Perez, M. A. (2017). Multilatinas and the internationalization of Latin American firms. Journal of World Business, 52(4), 447-460. https://doi. org/10.1016/j.jwb.2017.05.006.

Aldrighi, D. M., \& Postali, F. A. S. (2010). Business groups in Brazil. Em A. M. Colpan, T. Hikino, \& J. R. Lincoln (orgs.), The Oxford Handbook of business groups (pp. 353-386). Oxford University Press. https://doi. org/10.1093/oxfordhb/9780199552863.003.0013

América Economía. (2019, julho 19). Conozca las 500 empresas más grandes de Latinoamérica 2019. https:// www.americaeconomia.com/negocios-industrias/ estas-son-las-500-empresas-mas-grandes-de-latinoamerica-2019

Banco Votorantim (2018). Aliando diferenciais competitivos. https:// www.bancovotorantim.com.br/web/site/pt/banco/institucional/ parceria-com-o-banco-do-brasil/

Barbero, M. I. (2011). Los grupos económicos en la Argentina en una perspectiva de largo plazo (siglos XIX y XX). Em G. Jones, \& A. Lluch (eds.), El impacto histórico de la globalización en Argentina y Chile: empresas y empresarios (pp. 1-37). Temas.

Barbieri, C. (2008, outubro 11). Votorantim perde R\$ 2,2 bi com câmbio. Folha de S. Paulo, Mercado. https://www1.folha.uol.com.br/fsp/ dinheiro/fi1110200810.htm

Bonelli, R. (1998). As estratégias dos grandes grupos industriais brasileiros nos anos 90. Ipea.

Bull, B. (2013). Diversified business groups and the transnationalisation of the Salvadorean economy. Journal of Latin American Studies, 45(2), 265-295. https://doi.org/10.1017/S0022216X13000370

Caldeira, J. (2007). Votorantim 90 anos: uma história de trabalho e superação. Mameluco. 
Cardoso, R. F. (2013). Política econômica, reformas institucionais e crescimento: a experiência brasileira (1945-2010). Em P. C. Ferreira, F. Giambiagi, S. Pessôa, \& F. Veloso (orgs.), Desenvolvimento econômico: uma perspectiva brasileira (pp. 166-210). Elsevier.

Carney, M., Gedajlovic, E. R., Heugens, P. P., van-Essen M., \& van-Oosterhout J. H. (2011). Business group affiliation, performance, context, and strategy: A meta-analysis. Academy of Management Journal, 54, 437460. https://doi.org/10.5465/amj.2011.61967812

Castro, L. B. (2005). Privatização, abertura e desindexação: a primeira metade dos anos 90 (1990-1994). Em F. Giambiagi et al. (orgs.), Economia Brasileira Contemporânea (pp. 141-165). Elsevier.

Colpan, A. M., \& Hikino, T. (eds.) (2016). Business groups in the West: Origins, evolution and resilience. Oxford University Press \& Harvard Business School Research.

Colpan, A. M., \& Hikino, T. (2010). Foundations of business groups: Towards an integrated framework. Em A. M. Colpan, T. Hikino, \& J. R. Lincoln (orgs.), The Oxford Handbook of business groups (pp. 15-66). Oxford University Press. https://doi.org/10.1093/ oxfordhb/9780199552863.003.0002

Dalla-Costa, A., Drumond, C. E., \& Las-Heras, J. M. (2015). Empresas y grupos empresariales brasileños en perspectivas histórica. Em P. FernándezPérez, \& A. Lluch (orgs.), Familias empresarias y grandes empresas familiares en América Latina y España (pp. 189-217). Fundación BBVA.

Delios, A., \& Ma, X. (2010). Diversification strategy and business groups. Em A. Colpan, T. Hikino, \& J. Lincoln (eds.), The Oxford Handbook of business groups (pp. 717-742). Oxford University Press. https://doi. org/10.1093/oxfordhb/9780199552863.003.0026

Evans, P. (1980). A Tríplice Aliança: As multinacionais, as estatais e o capital nacional no desenvolvimento dependente brasileiro. Zahar.

Fernández-Perez, P., \& Casanova, L. (2012). Algunas claves de la longevidad de las grandes empresas familiares brasileñas. Apuntes, Universidad del Pacífico, 39(70), 273-300. https://doi.org/10.21678/apuntes.70.652

Fernández-Pérez, P., \& Lluch, A. (2015). Introducción. Em P. Fernández-Pérez, $\&$ A. Lluch (orgs.), Familias empresarias y grandes empresas familiares en América Latina y España (pp. 15-37). Fundación BBVA. 
Fundação Dom Cabral (2018). Ranking das transnacionais brasileiras.

Fundação Dom Cabral.

Fundação Dom Cabral (2009). Ranking das transnacionais brasileiras.

Fundação Dom Cabral.

Giambiagi, F. (2005). Estabilização, reformas e desequilíbrios

macroeconômicos: os anos FHC (1995-2002). Em F. Giambiagi et al.

(orgs.), Economia Brasileira Contemporânea (pp. 166-195). Elsevier.

https://doi.org/10.18356/3982e027-es

Global Cement (2018). Global Cement Top 100 Report 2017-

2018. https://www.globalcement.com/magazine/

articles/1054-global-cement-top-100-report-2017-2018

Granovetter, M. (2005). Business Groups and Social Organization. Em N.

Smelser \& R. Swedberg (orgs.), The Handbook of Economic Sociology

(2a ed., pp. 429-450). Princeton University Press. https://doi.

org/10.1515/9781400835584.429

Grupo Votorantim (2020). Relatório Anual do Grupo Votorantim para o ano:

2019. https://www.votorantim.com.br/

Grupo Votorantim (2019). Relatório Anual do Grupo Votorantim para o ano:

2018. https://www.votorantim.com.br/

Grupo Votorantim (2018). Relatório Anual do Grupo Votorantim para o ano:

2017. https://www.votorantim.com.br/

Grupo Votorantim (2017). Relatório Anual do Grupo Votorantim para o ano:

2016. https://www.votorantim.com.br/

Grupo Votorantim (2016). Relatório Anual do Grupo Votorantim para o ano:

2015. https://www.votorantim.com.br/

Grupo Votorantim (2015). Relatório Anual do Grupo Votorantim para o ano:

2014, 2015, 2016, 2017 e 2018 e 2019. https://www.votorantim.com.

$\mathrm{br} /$

Grupo Votorantim (1986). Relatório Anual do Grupo Votorantim para o ano:

1985. Centro de Memória Votorantim.

Grupo Votorantim (1984). Relatório Anual do Grupo Votorantim para o ano:

1983. Centro de Memória Votorantim.

Grupo Votorantim (1982). Relatório Anual do Grupo Votorantim para o ano:

1981. Centro de Memória Votorantim. 
Grupo Votorantim (1981). Relatório Anual do Grupo Votorantim para o ano: 1980. Centro de Memória Votorantim.

Grupo Votorantim (1979). Relatório Anual do Grupo Votorantim para o ano: 1980. Centro de Memória Votorantim.

Guillén, M. F. (2000). Business groups in emerging economies: A resourcebased view. Academy of Management Journal, 43(3), 362-380. https:// doi.org/10.5465/1556400

Instituto de Pesquisa Econômica Aplicada (2019). Dados macroeconômicos e regionais. Instituto de Pesquisa Econômica Aplicada.

Khanna, T., \& Yafeh, Y. (2007). Business groups in emerging markets: Paragons or parasites? Journal of Economic Literature, XLV, 331-372. https://doi.org/10.1257/jel.45.2.331

Khanna, T., \& Palepu, K. (1997). Why focused strategies may be wrong for emerging markets. Harvard Business Review, 75(4), 41-51.

Leff, N. H. (1974). El espíritu de empresa y la organización industrial en los países menos desarrollados: los grupos. El Trimestre Económico, $X L I(3), 87-105$.

Morceiro, P. C. (2018). A indústria brasileira no limiar do século XXI: uma análise da sua evolução estrutural, comercial e tecnológica (tese de doutorado, Universidade de São Paulo, Brasil).

Morceiro, P. C., \& Guilhoto, J. J. M. (2019). Desindustrialização setorial e estagnação de longo prazo da manufatura brasileira. Universidade de São Paulo, Working Paper Series No 2019-01. https://doi.org/10.5151/ iv-enei-2019-1.3-022

Ocampo, J. A., \& Ros, J. (2011). Shifting paradigms in Latin America's Economic Development. Em J. A. Ocampo, \& J. Ros (eds.), The Oxford Handbook of Latin American Economics (pp. 3-25). Oxford University Press. https://doi.org/10.1093/oxfordhb/9780199571048.001.0001

Pastore, J. (2013). Antônio Ermírio de Moraes - Memórias de um diário confidencial. Planeta do Brasil.

Pedrosa, R. P. A. (2015). Desafios do crescimento de empresas diversificadas: os casos Matarazzo e Votorantim. http://objdig.ufrj.br/41/ dissert/825954.pdf 
Rocha, M. A. M. (2013). Grupos econômicos e capital financeiro: uma história recente do grande capital brasileiro (tese de doutorado, Universidade Estadual de Campinas, Instituto de Economia, Campinas, Brasil). http://www.repositorio.unicamp.br/handle/REPOSIP/285912

Santos, L. B. (2013). Estado e internacionalização das empresas multilatinas. Cultura Acadêmica.

Santos, L. B. (2010). Os novos espaços de acumulação do Grupo Votorantim. Revista Ra'e Ga, 19, 79-95. https://doi.org/10.5380/raega. v19i0.14732

Santos, L. B. (2008). Reestruturação, internacionalização e novos territórios de acumulação do Grupo Votorantim. https://repositorio.unesp. br/bitstream/handle/11449/96707/santos_lb_me_prud. pdf? sequence $=1$ \&isAllowed $=y$

Schneider, B. R. (2010). Business Groups and the State: The politics of expansion, restructuring and collapse. Em A. Colpan, T. Hikino, \& J. Lincoln (eds.), The Oxford Handbook of business groups (pp. 650-669). Oxford University Press. https://doi.org/10.1093/ oxfordhb/9780199552863.003.0023

Silva, G. P., \& Dalla-Costa, A. J. (2021). Da fábrica sorocabana ao conglomerado nacional: uma análise da história do Grupo Votorantim (1891-1980). História Unisinos, 25(1), 133-149. https://doi. org/10.4013/hist.2021.251.11

Silva, G. P., \& Dalla-Costa, A. J. D. (2018a). A formação do Grupo Votorantim: as origens de um grupo econômico brasileiro no setor têxtil de São Paulo (1891-1929). Econ. Soc., 27(1), 321-354. http://dx.doi. org/10.1590/1982-3533.2017v27n1art11

Silva, G. P., \& Dalla-Costa, A. J. A. (2018b). Fábrica Votorantim e o setor têxtil paulista (1918-1939): os caminhos que levaram o grupo da falência à liderança industrial. Nova Econ., 28(2), 579-607. http://dx.doi. org/10.1590/0103-6351/3448

Sindicato Nacional da Indústria do Cimento (2019). O consumo de cimento no Brasil em 2018. https://cimento.org/ venda-de-cimento-no-brasil-em-2018/ 
Yang, X., Jiang, Y., Kang, R., \& Ke, Y. (2009). A comparative analysis of the internationalization of Chinese and Japanese firms. Asia Pacific Journal of Management, 26(1), 141-62. https://doi.org/10.1007/ s10490-007-9065-0

Yaprak, A., \& Karademir, B. (2010). The internationalization of emerging market business groups: An integrated literature review. International Marketing Review, 27(2), 245-262. https://doi. org/10.1108/02651331011037548 